\title{
PSYCHIATRY IN GENERAL PRACTICE
}

PhILIP Hopkins, M.R.C.S.

General Practitioner, 249 Haverstock Hill, Hampstead, N.W.3

Psychiatry is becoming increasingly more important in general practice and this is reflected in the growing volume of literature contributed by family doctors. This is not simply a matter of attaching diagnostic labels to patients before referring them to consultant psychiatrists for disposal, but rather the more frequent use of what might be termed a psychiatric approach in medical practice.

This is far removed from the generally accepted definition of the word psychiatry which is still given as 'that branch of medicine which deals with the recognition and treatment of diseases of the mind ' (Stedman's Medical Dictionary, 1958), since one is dealing more with disorders of the emotional state rather than with 'diseases of the mind'.

It is well known that great advances have been made in many branches of medicine, particularly in the development of techniques of diagnostic and surgical procedures, in chemotherapy of infectious diseases, and in many other scientific achievements. Nevertheless, in the Report of the Ministry of Health for the Year $195^{32}$ the Chief Medical Officer has recorded that: 'In no field of medicine have there been more marked changes than in psychiatry since the introduction of the National Health Service'. He notes the change in attitude towards mental disorder so that it is becoming more acceptable as an illness and, further, psychiatry and general medicine are being integrated, with benefit to both. One of the results of these changes is the shift of emphasis from treatment in mental hospitals to the treatment of patients within the community. This must bring more patients under the care of their family doctors.

Unfortunately the teaching of psychiatry appears not to have kept up with the changes reported, but rather to have remained under the influence of Kraepelin (1855-1926) in that many consultants in the practice and teaching of psychiatry continue in their search for organic causation of mental illness in every case, as has recently been pointed out by Dr. William H. Shepley. ${ }^{33}$

The teaching of psychiatry in most medical schools still consists of a series of six, sometimes more, lectures together with demonstrations of the more florid psychoses. Normal psychology is seldom taught, while the subject of psychodynamics is rarely mentioned.*

It is hardly the fault of the newly qualified doctor, therefore, if he regards psychiatry as that branch of medicine that deals with 'diseases of the mind '-lunatics and psychotics-and prefers not to deal with such patients.

Reference to current text-books of psychiatry will show that mental disorders are usually classified according to the type of reaction, and other conditions defined in terms that are hardly specific. Table $I$ is something of a composite picture of psychiatry as it is taught to-day.

Tables 2 and 3 show the diagnoses with their distribution according to age and sex in 225 consecutive new patients suffering from psychiatric illness seen in my practice. This group constitutes $11.1 \%$ of the total number of patients seen during the survey, thus it can be seen that even pure psychiatric illness accounts for a fair proportion of the work in my practice. Especially is this so when it is realised that a very small number of these patients had to be referred to a consultant psychiatrist for treatment outside the competence of a family doctor.

A number of surveys have been carried out in an effort to estimate the incidence of psychiatric illness in general practice and the findings of those available to me are shown in Table 4.

The wide variation, from $6.5 \%$ to $20.2 \%$ in the incidence of psychiatric illness, may be explained in part by the differences in terminology used by the authors, and by recognition of the fact that many patients ' mask' their psychoneurotic states by presenting with symptoms which are frequently used as diagnostic labels.

* The British Medical Students' Association's ' Report on the Teaching of Psychiatry and Psychological Medicine' has just come to the author's attention. This report shows more clearly the considerable need for improvement in the medical curriculum, and will be of interest to all who are concerned about this most important aspect of the subject. As C. Newman ${ }^{28}$ has so aptly written: "The safeguard of the future lies in medical education'. 
TABle 1.

\begin{tabular}{l|l}
\hline \multicolumn{1}{c|}{ Disorder } & \multicolumn{1}{c}{ Types } \\
\hline Affective reaction types & $\begin{array}{l}\text { (a) Manic-depressive } \\
(b) \text { Involutional melancholia }\end{array}$ \\
\hline Schizophrenic reaction types & $\begin{array}{l}\text { (a) Hebephrenic } \\
\text { (b) Paranoid } \\
\text { (c) Katatonic }\end{array}$ \\
\hline
\end{tabular}

\begin{tabular}{lllll}
\hline Paranoid reaction types & $\ldots$ & $\ldots$ & $\ldots$
\end{tabular}

(a) Paranoia

(b) Paraphrenia

Organic reaction types

(a) Acute (mainly infectious or toxic in origin), e.g. delirium, alcohol

(b) Chronic (mainly degenerative), e.g. senile and arterio-sclerotic, brain tumours, etc.

Denoting a large group of disorders characterized by impulsive behaviour, emotional instability and a pathological inability to learn from experience. (According to the Mental Health Act, 1959-H.M.S.O. ${ }^{26}$ - the term psychopathic disorder is to mean a persistent disability or disorder of the mind (whether or not including subnormal intelligence) which results in abnormally or seriously irresponsible conduct on the part of the patient and requiring medical treatment.)

This, of course, is characterized by the occurrence of fits (major or minor), but in many cases with a character-change which is typically selfish, childish and with little depth of feeling, and often with a secondary intellectual defect of attention, memory and comprehension

Epilepsy

Mental deficiency

(a) Intellectual defect states

(b) Temperamental defect states or 'constitutional psychopathic inferiority,
(a) Impotence
(b) Ejaculatio praecox
(c) Frigidity
(d) Dyspareunia
(e) Homosexuality
(f) Sadism and masochism
(g) Exhibitionism
(h) Fetichism
(a) Anxiety states
(b) Hysteria
(c) Obsessive and compulsive states
(d) Depressive states
(e) Phobias

Psychoneuroses

TABLE 2.

\begin{tabular}{|c|c|c|c|c|c|c|c|c|c|c|c|c|c|c|c|c|c|c|}
\hline & \multirow{3}{*}{ Diagnosis } & \multirow{2}{*}{\multicolumn{2}{|c|}{$10-19$}} & \multicolumn{6}{|c|}{ Age and sex } & & & & & & & & & \\
\hline & & & & \multicolumn{2}{|c|}{$20-29$} & \multicolumn{2}{|c|}{$30-39$} & \multicolumn{2}{|c|}{$40-49$} & \multicolumn{2}{|c|}{$50-59$} & \multicolumn{2}{|c|}{$60-69$} & \multicolumn{2}{|c|}{ Over 70} & \multicolumn{3}{|c|}{ Totals } \\
\hline & & $\mathbf{M}$ & $\mathbf{F}$ & $\mathbf{M}$ & $\mathbf{F}$ & $\mathbf{M}$ & $\mathbf{F}$ & $\mathbf{M}$ & $\mathbf{F}$ & $\mathbf{M}$ & $\mathbf{F}$ & $\mathbf{M}$ & $\mathbf{F}$ & $\mathbf{M}$ & $\mathbf{F}$ & $\mathbf{M}$ & $\mathbf{F}$ & All \\
\hline $\begin{array}{l}\text { Anxiety states } \\
\text { Depressive states } \\
\text { Hysteria } \ldots \\
\text { Manic state . . } \\
\text { Obsessional states } \\
\text { Schizophrenia }\end{array}$ & $\begin{array}{l}\ldots \\
\cdots \\
\cdots \\
\cdots \\
\cdots\end{array}$ & $\mathbf{I}$ & 5 & $\begin{array}{r}\mathbf{1} \\
\mathbf{I} \\
\mathbf{I}\end{array}$ & $\begin{array}{r}29 \\
6 \\
4\end{array}$ & 10 & $\begin{array}{r}24 \\
4 \\
2 \\
\\
2\end{array}$ & $\begin{array}{l}10 \\
1 \\
1\end{array}$ & $\begin{array}{r}30 \\
2\end{array}$ & $\begin{array}{l}6 \\
1 \\
3 \\
2\end{array}$ & $\begin{array}{r}17 \\
5\end{array}$ & 7 & $\begin{array}{l}5 \\
6\end{array}$ & $\begin{array}{l}\mathbf{I} \\
\mathbf{I}\end{array}$ & $\begin{array}{l}5 \\
3\end{array}$ & $\begin{array}{r}47 \\
2 \\
6 \\
1 \\
3 \\
1\end{array}$ & $\begin{array}{r}115 \\
26 \\
6 \\
- \\
2 \\
1\end{array}$ & $\begin{array}{r}162 \\
28 \\
12 \\
1 \\
5 \\
2\end{array}$ \\
\hline \multirow[t]{2}{*}{ Totals .. } & . & $\mathbf{I}$ & 5 & I 5 & 40 & I I & 32 & 12 & 32 & 12 & 22 & 7 & I I & 2 & 8 & 60 & 150 & \multirow[t]{2}{*}{210} \\
\hline & & \multicolumn{2}{|c|}{6} & \multicolumn{2}{|c|}{55} & \multicolumn{2}{|c|}{43} & \multicolumn{2}{|c|}{44} & \multicolumn{2}{|c|}{34} & \multicolumn{2}{|c|}{18} & \multicolumn{2}{|c|}{10} & \multicolumn{2}{|c|}{210} & \\
\hline
\end{tabular}


TABLE 3.

\begin{tabular}{|c|c|c|c|c|c|c|c|}
\hline \multirow{3}{*}{ Diagnosis } & \multicolumn{4}{|c|}{ Age and sex } & \multirow{2}{*}{\multicolumn{3}{|c|}{ Totals }} \\
\hline & \multicolumn{2}{|c|}{$0-1$} & \multicolumn{2}{|c|}{$2-9$} & & & \\
\hline & $\mathbf{M}$ & F & $\mathbf{M}$ & F & $\mathbf{M}$ & $\mathbf{F}$ & All \\
\hline $\begin{array}{l}\text { ' Behaviour problems' } \\
\text { ' } \text { Feeding problems '.. } \\
\text { Enuresis . } \\
\text { N.A.D. . parental anxiety } \\
\text { PUO N.A.D. . . . }\end{array}$ & $\frac{\overline{2}}{\overline{2}}$ & $\begin{array}{l}- \\
\text { I } \\
- \\
-\end{array}$ & $\overline{-}$ & $\begin{array}{l}2 \\
- \\
- \\
2\end{array}$ & $\begin{array}{l}- \\
2 \\
1 \\
7 \\
-\end{array}$ & $\begin{array}{l}2 \\
1 \\
- \\
2\end{array}$ & $\begin{array}{l}2 \\
3 \\
1 \\
7 \\
2\end{array}$ \\
\hline \multirow[t]{2}{*}{ Totals } & 4 & I & 6 & 4 & 10 & 5 & 15 \\
\hline & & \multicolumn{2}{|c|}{10} & \multicolumn{3}{|c|}{ I 5} \\
\hline
\end{tabular}

TABle 4.

\begin{tabular}{|c|c|c|c|c|}
\hline \multicolumn{3}{|c|}{ Author } & \multirow{2}{*}{$\begin{array}{l}\begin{array}{l}\text { Year of } \\
\text { survey }\end{array} \\
1947-48\end{array}$} & \multirow{2}{*}{$\begin{array}{c}\begin{array}{c}\text { Percentage of } \\
\text { psychiatric } \\
\text { illness }\end{array} \\
8.0\end{array}$} \\
\hline Chapman $^{4}$ & . & . & & \\
\hline Crawford $^{6}$ & . & $\cdots$ & $1951-52$ & 16.7 \\
\hline Crawford & .. & $\ldots$ & $1952-53$ & 15.6 \\
\hline Fry $^{8}$ & .. & . & $195^{1-53}$ & I 1.5 \\
\hline Hopkins ${ }^{14}$ & .. & . & $195 \mathrm{I}$ & I I.I \\
\hline Jansen $^{19} \ldots$ & . & . & 1954 & 12.0 \\
\hline $\operatorname{Logan}^{22}$ & .. & .. & $1951-52$ & $20.2^{*}$ \\
\hline Logan and $C$ & hion ${ }^{23}$ & . & $1955-56$ & $18.2^{*}$ \\
\hline McGregor $^{24}$ & . & .. & $1948-49$ & 6.8 \\
\hline Pemberton $^{30}$ & . & .. & I947 & 6.5 \\
\hline Watts $^{36}$ & $\ldots$ & & I $947-50$ & 12.2 \\
\hline
\end{tabular}

*These figures are the percentages of the total number of consultations, and are included in the two reports on 'Morbidity Statistics from General Practice,' which were based on a statistical study of the clinical records of eight in the first study and 106 general practices in the second. This work was carried out jointly by the College of General Practitioners and the General Register Office.

What might be called gastritis by one doctor becomes an acute anxiety state with dyspepsia in the records of another. Study of the tables of figures given by Logan and Cushion ${ }^{23}$ shows clearly that there is a large number of conditions which are in themselves vague and indefinite, yet are used as diagnostic labels. A few examples are self-explanatory, and are shown in Table 5 .

It seems reasonable to assume that if these conditions had been found to be due to some physical disease they would have been put under the appropriate headings.
TABLE 5 .

\begin{tabular}{|c|c|c|}
\hline Diagnosis & $\begin{array}{c}\text { International } \\
\text { Classification } \\
\text { No. }\end{array}$ & $\begin{array}{c}\text { Percentage } \\
\text { patients } \\
\text { consulting }\end{array}$ \\
\hline $\begin{array}{cc}\begin{array}{c}\text { Functional disease } \\
\text { heart }\end{array} & \begin{array}{c}\text { of } \\
\cdots\end{array} \\
\end{array}$ & 433 & 0.33 \\
\hline $\begin{array}{c}\text { Disorders of function of } \\
\text { stomach }\end{array}$ & 544 & 2.15 \\
\hline 'Menopausal symptoms' & 635 & $\mathbf{1 . 8 5}$ \\
\hline 'Vertigo' $\quad$. & 780.6 & 0.06 \\
\hline 'Disturbance of sleep'.. & 780.7 & 0.56 \\
\hline 'Cough' $\quad$. & $783 \cdot 3$ & 2.07 \\
\hline 'Pain in chest' & $783 \cdot 7$ & 0.08 \\
\hline ' Nausea and vomiting' & 784.1 & 0.66 \\
\hline 'Abdominal pain' & $785 \cdot 5$ & 0.82 \\
\hline $\begin{array}{c}\text { Other specified and } \\
\text { general symptoms }\end{array}$ & $780-789$ & 2.5 \\
\hline 'Nervousness'.. & 790.0 & 0.19 \\
\hline $\begin{array}{r}\text { Debility , and undue } \\
\text { fatigue }\end{array}$ & 790.1 & 0.56 \\
\hline 'Depression' .. & 790.2 & 0.29 \\
\hline 'Headache' .. & 791 & 0.59 \\
\hline
\end{tabular}

By studying papers by specialists in different fields it becomes evident that such physical symptoms are frequently not based on physical disease, so the scope for psychiatry in general practice is even greater than indicated above.

There are large numbers of patients with bodily symptoms, mostly associated with autonomic nervous system dysfunction.

Cassidy $^{3}$ noted that $29.5 \%$ of patients seen by him as a consulting cardiologist showed no evidence of cardio-vascular disease.

Menninger ${ }^{25}$ states that 'the gastrointestinal tract mirrors the emotions better than any other body system ' and $\mathrm{Hardy}^{12}$ gives the incidence of functional disorders of the colon at $20-30 \%$ of all abdominal conditions.

The work described by Wolf and Wolff, ${ }^{37}$ and by Grace, Wolf and Wolff ${ }^{9}$ was carried out on human subjects with gastrostomy or prolapsed colonic mucosa. The objective changes in the mucosa of the stomach and colon were studied in relation to physiological stimulation, pharmacological action of drugs and, most revealing of all, to the effect of life situations and emotional states. It was found that resentment and anger resulted in diarrhoea, whilst depression and dis- 
content were liable to produce constipation. Groen $^{10}$ noted that grief often precedes the onset of ulcerative colitis and Davis and Wilson ${ }^{7}$ showed that in $84 \%$ of their patients with peptic ulcer symptoms began soon after some event affecting the patient's work, finances or the health of his family, as compared with $22 \%$ of a control group of patients with hernia.

Paulley $^{29}$ has listed the disorders of the gut in which he considers that emotional factors, or stress,* plays a part in the aetiology. He emphasises the prime need for the fullest understanding of personality pattern in each disorder and of the kinds of situation likely to provoke attacks. $\mathrm{He}$ describes in some detail the importance of a psychiatric approach in managing patients with duodenal ulcer, ulcerative colitis and Crohn's disease.

The skin also expresses the emotional state very clearly and it is not surprising that patients frequently present with skin lesions when, in fact, they are suffering from emotional disturbances. Sneddon ${ }^{34}$ classifies skin conditions in which there is a psychogenic factor as follows:

Group 1. Dermatoses always psychic in origin:

(a) Delusions of parasitosis and other obsessional states.

(b) Dermatitis factitia.

(c) Neurotic excoriations.

(d) Trichotillomania.

Group 2. Dermatoses with a large psychogenic factor:

(a) Neurodermatitis.

(b) Pruritus ani et vulvae.

(c) Atopic eczema.

(d) Nummular eczema.

(e) Rosacea.

Group 3. Dermatoses sometimes precipitated by psychogenic factors:

(a) Urticaria.

(b) Hyperidrosis.

(c) Cheiro-pompholyx.

(d) Seborrhoeic dermatitis.

(e) Psoriasis.

(f) Alopecia areata.

In the realms of gynaecology it is still not yet widely recognized that emotional tension can and does produce a variety of menstrual disorders as well as creating difficulties at the climacteric. I have reported a study of a group of women in the climacteric ${ }^{13}$ and shown that those having depression or other psychological symptoms at the time of the climacteric, have already been under emotional stress prior to its onset. I have

* The word ' stress' is used according to the definition given by Wolff ${ }^{37}$ as meaning the internal or resisting force brought into being in the human organism by interaction with the environment. reported elsewhere ${ }^{\mathbf{1 8}}$ my findings in a survey covering 178 women who consulted me with gynaecological symptoms. Ninety-four of these patients complained of menstrual disorders, the large majority of which proved to be based on emotional tension.

At a Symposium on Menorrhagia held by the Society for Psychosomatic Research ${ }^{17}$ I described my findings in 17 women with menorrhagia psychogenica. In addition to the menorrhagia, all of them complained of various other symptoms such as disturbance of digestion and/or bowels, palpitations, feelings of weakness, headaches and insomnia; most of them were obviously anxious or depressed. In all 17 patients it was possible, by allowing them sufficient time to talk about themselves and their life situations, to elicit very real stress factors, following which many of them were very much improved.

A large group of patients come to their doctor complaining of ' rheumatism '-usually signifying that they have some vague ache or pain somewhere, or at times, everywhere. Copeman ${ }^{5}$ refers to ' psychic stress', ' hyper-excitable individuals', 'mental fatigue', ' emotional shock' and other such terms when discussing the aetiology of rheumatic conditions. In the section devoted to fibrositis he says 'fibrositis is one of the diseases of stress, and its victims must be relaxed mentally and physically'. In discussing rheumatoid arthritis he states: 'I have seen several cases recently who date the onset of their symptoms to a near miss during the bombing of London in 1940-4I'. Le Vay ${ }^{21}$ not only denies the existence of fibrositis as a clinical entity but he writes: ' psychological factors are often the cause of what is usually regarded as gross physical orthopaedic disease ; . . . emotion may greatly modify muscular tension, posture and even osseous structure; these end-results may completely obscure the prime causes; and the physical outcome is often of symbolic value to the patient'.

All these writers indicate that in many patients seen by them as specialists, there are symptoms without palpable physical or ' organic' cause-in fact these are generally the patients who ultimately are referred back from hospital out-patient clinics to their family doctor with the letter advising that 'there is nothing wrong'. In fact these patients are suffering from stress disorders or, for those who prefer the term, psychosomatic disorders, and in the same way that Koch's postulates have been used as criteria for the aetiology and diagnosis of infectious diseases so there are criteria, as I have described in an earlier paper, ${ }^{14}$ for the diagnosis of a stress disorder which (I) starts at a time of crisis or special stress, (2) varies in its course wth the degree of stress and (3) clears with the altera- 
Table 6.

\begin{tabular}{|c|c|c|c|c|}
\hline \multicolumn{3}{|c|}{ Author } & \multirow{2}{*}{$\begin{array}{c}\begin{array}{c}\text { Year of } \\
\text { survey }\end{array} \\
\text { I95I }\end{array}$} & \multirow{2}{*}{$\begin{array}{c}\begin{array}{c}\text { Percentage of } \\
\text { psychiatric and } \\
\text { stress disorders }\end{array} \\
42.2\end{array}$} \\
\hline Hopkins ${ }^{14}$ & . & .. & & \\
\hline Hopkins ${ }^{15}$ & .. & . & $195 x-53$ & $31 \cdot 3^{*}$ \\
\hline Jansen $^{1 \theta}$ & - & $\cdots$ & 1954 & 32.0 \\
\hline McGregor ${ }^{24}$ & $\cdots$ & $\cdots$ & I 948-49 & 23.6 \\
\hline Mestitz 27 & . & $\cdots$ & 1957 & $27.0 \dagger$ \\
\hline Pougher $^{31}$ & $\cdots$ & . & 1953 & $36.2-47.6$ \\
\hline
\end{tabular}

*This indicates the percentage of all patients referred to hospital during $195 \mathrm{I}-53$ for investigation and specialist opinions.

†This indicates the percentage of 1,817 patients seen in a casualty department in whom no organic cause had been found for their symptoms.

tion of the circumstances responsible for the stress, or in the adaptation of the patient to the situation. A fourth criterion might well be that the illness will persist, or tend to recur if treatment consists only of physical methods directed at the symptoms.

Table 6 shows the incidence of both psychiatric and stress disorders as reported by several who have carried out surveys in this wider field.

There is still a marked variation in the figures, but at a fairly high level-and even accepting the lower figures they imply that between a quarter and a third of the patients seen in general practice require some form of psychiatric treatment rather than an orthodox medical approach. Yet many of these patients are suffering from conditions for which they would rarely have been referred to a consultant psychiatrist, nor is there need for this. The majority of them can be treated by the family doctor.

The place for psychiatry in general practice, then, is universal and the scope enormous. This does not imply that the general practitioner should try to become an ' amateur psychiatrist' any more than he attempts to be an ' amateur paediatrician' when he is treating children in his practice, or an ' amateur cardiologist' when he is looking after his patients with heart disease. It means simply that the doctor in general practice should be prepared to use any special techniques that come within his competence, including those he may learn from the psychiatrist as well as the various other special techniques of examination and treatment that he has learned as a student and hospital resident from the consultant surgeons and physicians.

It has been said that the general practitioner is in the front line in the fight against disease, presumably because people who feel themselves to be ill in some way usually turn first to him. The family doctor is therefore the first to have the opportunity of deciding the nature of the illness and of choosing the type of treatment required and, of course, he is on the spot to apply it, if within his competence. It is most important to recognize that the doctor's attitude to his patient's illness may influence not only the course of the illness but also, in many cases, perhaps the course of the patient's future life.

If the doctor has not the time to make the diagnosis of a psychiatric or psychosomatic illness, nor perhaps the courage of his conviction, because of the presence of physical symptoms (even though no physical disease has been found by a thorough clinical examination), there is the danger that the patient will be started on the hospital rounds leading, as it so often does, to many unnecessary specialist examinations and much unnecessary prescribing of medicines.

Michael Balint ${ }^{1}$ has aptly described this as ' the process of dilution of responsibility' leading to 'the collusion of anonymity'. In this way no one doctor is responsible for the patient who is often allowed to drift from one specialist department to another within the hospital.

On the other hand, if a psychiatric approach is adopted, and in my own experience it has certainly proved to be well worth while, it is necessary only to ensure that sufficient time is available for each patient. Good medical practice must necessarily involve the use of time, as it is only by allowing each patient as much time as is required for full history taking and thorough physical examination that a correct diagnosis can be made. Only then can the appropriate treatment be applied.

It is generally not possible to spend more than a few minutes with a patient during routine 'surgery hours' so that when a new patient first attends it is important to hear the symptoms, to make sure that there is nothing urgent about the illness and then to indicate to the patient that the condition will clearly require more time than is at present available; an appointment is offered, making it clear that there will then be ample time for him to tell the doctor all about his illness.

I have seldom had difficulty with this approach and, indeed, most patients appear to appreciate the opportunity of coming back by appointment.

Ideally, a first interview requires an hour, although much can be done in 45 minutes and at times even half-an-hour. It may not be possible to do more than take a full history at the first interview, in which case a further appointment is given for the physical examination and discussion about the possible future treatment. 
As a result of the first interview a diagnosis will have been made, or possibly various special investigations may have been thought necessary and arranged. Assuming that the patient has been found to be suffering from a psychiatric or stress disorder, it would now be necessary to decide whether treatment is to be along physical lines (either by prescribing by the general practitioner, or by referral to a consultant psychiatrist) or whether the treatment will consist of psychotherapy. Possibly a combination of prescribing* and psychotherapy may be decided upon.

I have found that, apart from the relatively small number of psychotic patients who can be kept under supervision and helped by supportive therapy, most other patients can be expected to benefit from psychotherapy.

Before proceeding further, however, it is as well to consider what is meant by the term psychotherapy, and may I say at once that it does not imply any one specific treatment. There are many forms of psychotherapy, and in the first place they may be conveniently divided in the same way that surgery is divided-into major and minor branches. ${ }^{16}$

Major psychotherapy includes psycho-analysis, narco-analysis, hypno-analysis and other forms of intensive psychotherapy and clearly would be used only by the specialist, and possibly by those few general practitioners who have had a personal training analysis. We are not here concerned with these methods.

Minor psychotherapy may also be divided into two further groups of methods. The first group of methods of minor psychotherapy includes the following:

I. Simple reassurance, usually after full examination has excluded physical disease.

2. Reassurance and the prescribing of a placebo.

3. 'Education' or explanation about some medical problem previously the basis of anxiety alone or with symptoms.

4. Sympathetic listening to the expression of difficult reality situations, or of resentments, discontent, aggressive feeling, etc., without show of reproach or condemnation.

5. Support and encouragement to continue in the face of difficulty.

6. Guidance to a happier and fuller use of leasure-time, and to the development of new

* The careful use of simple sedatives, such as amylobarbitone, gr. $\frac{1}{2}$ b.d. or t.d.s., and of hypnotics for nighttime are of great value as an adjunct to psychotherapy, and it is only for the more seriously disturbed neurotic or the psychotic for whom it is necessary to prescribe any of the so-called tranquillizers; the reader is referred to the appropriate textbooks for detailed information. hobbies and interests. Possibly, suitable books may be recommended for reading.

7. The proverbial 'bed-side manner' might also be placed under the heading of minor psychotherapy, and there must be many other forms of this art.

All these methods are probably used by family doctors throughout Britain in their day-to-day dealings with their patients - even by those who still regard the terms psychiatry and psychotherapy as rude words!

But these methods have one thing in commonthey do not attempt to deal with underlying emotional conflicts or problems any more than prescribing the more usual physical treatments, even though they may allow the doctor a fuller understanding of the patient as a whole person and not merely as the vehicle for symptoms.

The second group of methods of minor psychotherapy are rather more advanced but are still within the competence of the family doctor. These methods are consciously and deliberately applied with careful thought and attention to what is going on between the patient and doctor. The aim is to focus the patient's attention on his mind, thereby helping him to understand his particular problems so that he is enabled either to find a way of resolving them, or if this is not possible, of adapting his way of life to fit in with them.

These psychotherapeutic methods consist of discussions with the patient about his present-day problems in the first place, and in such a way that underlying emotional conflicts can be related to them. Where the patient denies problems, or is clearly unaware of any conscious anxieties or worries, it is necessary to centre discussions on the life situation at the time of the onset of the illness, or even on the whole life history in order to discover possible motivation for his present-day behaviour and the development of the symptoms.

I have found it most helpful to apply to the patient the questions suggested by Halliday: ${ }^{11}$ (1) What kind of person was this? (2) Why did he become ill when he did? and (3) Why did he become ill in the manner he did?

Essentially the aim is to encourage the patient to do the talking - the reverse of normal medical history taking-as the relative material is in the patient's mind and only he can produce it. It is surprising how often the patient can be helped to discover solutions to his underlying emotional problems in this way. Repeated description of his symptoms should be gently discouraged and, at all times, the discussion should be directed at what lies behind the symptoms. That is, what do the symptoms do for him or what does he do with them?

A. B., a 29-year-old married man complained 
of indigestion for one week-he had flatulence after food and this was associated with frontal headaches. He volunteered the statement that he ' could not understand it at all as he had no worries'. A previous doctor had treated him for indigestion and headaches some months previously and, in spite of following a careful diet, the patient was puzzled as to why he should still have symptoms.

He accepted the suggestion to come back for full examination by appointment and, although he insisted that nothing was worrying him, he remembered that some three years earlier he had had similar symptoms as his wife's pregnancy drew to a close and during the first few weeks after the baby was brought home from the maternity hospital.

By the end of the third session it was apparent that Mr. A. B. was a very conscientious and selfdriving individual. He had been afraid of his father and feared anyone in a position of authority. He was always afraid of doctors and it was with a sense of relief that he found himself able to discuss his life with me. He was insistent that all was well at home so I encouraged him to talk about his work. To his surprise he was soon talking about a difficult relationship that had sprung up between himself and his immediate senior at work. By the end of the fifth session, three weeks after I had first seen him, he was feeling considerably better and had decided to approach this man with a view to settling certain differences between them. One month later he reported that they had been able to reach agreement and there was no further trouble. His indigestion had cleared up, he had no more headaches, and life was very much more satisfactory than it had been for some time.

Had this man been referred to hospital for specialist examinations and routine $\mathrm{X}$-rays, he might well have become a chronic dyspeptic-a regular attender at the surgery for bottles of medicine- or even developed a duodenal ulcer with its possible complications.

This is a typical example of the doctor's attitude not only helping the patient to understand the relationship between his emotional state and his symptoms, but also helping him to see what practical steps to take to improve his work situation. This is also a good example of the worthlessness of accepting the patient's own statement during the first interview that he has ' no worries'.

C. D., a 2 I-year-old man, moved to this district and consulted me on account of ' recurrent boils and frequent colds'. His previous doctor had given him a variety of treatments but without success.

He accepted an appointment for full examination and discussion of his situation, and after only two sessions it became quite clear that he not only disliked living away from his home town, but he was also following an occupation chosen for him by his father instead of what he had wanted.

In addition, there was also a problem involving a recent love-affair.

Full discussion over two more interviews resulted in his making the important decision that he would go home for a weekend and discuss the problems openly with his father. This he did, along the lines that he discussed first with me, and subsequently he returned to London very happy with the knowledge that his father had admitted his own mistake in forcing him to pursue a career that did not interest him, and agreed that he should give it up and return to university to study the subject of his own choosing. During the few weeks that he remained in London his general health improved remarkably, and I have since heard from him that he is extremely well and happy, in spite of having to work very hard at his new studies.

It is essential to base the diagnosis of a psychoneurotic or stress disorder on a positive history which must fulfil the criteria described above. In this way the danger of missing some serious malignant disease (a fear well instilled into all doctors during their early years of training) will be avoided.

E. F., a 48-year-old man, told me that his previous doctor had advised him that he needed treatment for his ' nerves'. The history was that of persistent pain at the left shoulder, for which no physical cause had been found at hospital three months earlier. It was apparently decided, by this process of elimination, that his pain must therefore be due to his ' nerves'.

Therc was nothing in the recent history to suggest any change in his emotional state, and when I came to examine him physically, despite his protest that this was unnecessary, there were signs at the left apex. Subsequent repeat chest $\mathrm{X}$-ray examination showed a carcinoma of the upper lobe of the left lung invading the first three ribs. He made a very satisfactory recovery from an extensive surgical excision of the lesion and has remained well until now.

I believe that as much harm may result from accepting presenting symptoms at their face value and treating them with physical methods, as from mis-diagnosing a carcinoma of the lung as 'nerves.' It is of equal importance that a proper diagnosis be made before treatment is started, in all cases.

Only in this way is it possible to apply safely psychiatric methods of treatment in general practice. Working psychotics can be supervised, and patients with psychoneurotic or psychosomatic 
disorders treated by psychotherapy or medication (or a combination of both) by the family doctor, so that the doctor who is interested in people, and not simply' in diseases, is most likely to be able to help the majority of his patients in his own consulting room. I entirely disagree with those who say that general practitioners should not indulge in psychotherapy. The family doctor is not only in the best place to assess the need for psychotherapy, but he sees the patient at the earliest possible time to use it, so that it can be most effective. This is particularly true for those patients whose difficulties involve relationships with other people. When the need arises the family doctor is able to see the patient with the other person (or persons), thus a husband and wife, or a mother and daughter, or any family group can be seen and helped together.

Finally, patients who are physically ill may also need psychiatric help, so that I would conclude with the borrowed words and wisdom of LangdonBrown ${ }^{20}$ : '. . . not only is psychoneurosis the only basis for many ills apparently physical, but all physical ills have their psychical aspect'.

\section{REFERENCES}

I. BALINT, M. (r957), "The Doctor, his Patient and the Illness.' London: Pitm?n Publishing Co.

2. BERGEN, H. (1956), N.Y. St. F. Med., 56, 1783.

3. CASSIDY, M. A. (1934), Brit. med. F., i, 45 .

4. CHAPMAN, H. O. (I953), Med. F. Aust., if, 407.
5. COPEMAN, W. S. C. (1946), ' The Treatment of Rheumatism in General Practice,' 4th edition. London: Arnold.

6. CRAWFORD, J.C. C. (1054), Brit. $千$. prev. soc. Med., 8, 81

7. DAVIES, D., and WILSON, A. T. M. (1937), Lancet, ii, 1353.

7. DAVIES, D., and WILSON, A. T. M. (1937)

9. GRACE, W. J., WOLF, S., and WOLFF, H. G. (1951), 'The Human Colon.' London: Oxford University Press.

10. GROEN, J. (1947), Psychosom. Med., 9, 151.

11. HALLIDAY, J. L. (1948), 'Psychosocial Medicine.' London: William Heinemann $\mathrm{Ltd}$

12. HARDY, T. L. (1934), Brit. med. F., vi, 637.

13. HOPKINS, P. (1954), Hunterian Trans., 13, 90.

13. HOPKINS, $\dot{P}$. (1954), Hunterian Trans., 13, 90. Psychosomatic Medicine,' Chapter I. London: Butterworth.

5. HOPKINS, P. (1956), Brit. med. Э., ii, 873 .

16. HOPKINS, P. (1956), Lancet, ii, 455.

17. HOPKINS, P. (1959), Ұ. Coll. Gen. Pract., 2, 246.

18. HOPKINS, P. (1959), Med. Wld. (Lond.), 90, 531 .

19. JANSEN, M. G. (1954), Med. F. Aust., ii, 422.

20. LANGDÓN-BROWN, SIR W. (1935), Brit. med. F., 1, 909.

21. LEVAY, A. D. (1947), Lancet, i, 125. Subjects,' No. 7, Report of the Registrar General. London: H.M.S.O., 1953 .

23. LOGAN, W.' P. D., and CUSHION, A. A. (1958), 'Morbidity Statistics from General Practice,' Vol. I (General), General Register Office, 'Studies on Medical and Population Subjects' No. I4,

MCGREGOR, R. M. (1050), Edinb. med. F., $57,433$.

25. MENNINGER, W. C. (1947), Psychosom. Med., 9, 92.

26. "Mental Health Act, 1959.' London: H.M.S.O.'

26. 'Mental Health Act, 1959' London: 1 H.M.

28. NEWMAN, C. (1957), 'Evolution of Medical Education in the Igth Century.' Oxford University Press.

29. PAULLEY, J. W. (1959), Brit. F. clin. Pract., 13, 314.

30. PEMBERTON, J. (1949), Brit. med. Ғ., i, 306 .

31. POUGHER J. C. E. (1955), Brit. med.' Y., ii, 400

32. 'Report of Ministry of Health for 1958,' Part. 2. H.M.S.O.,

33. SHEPLEY, W. H. (1959), Brit. med. 7., ii, 958.

34. SNEDDON, I. B. (1949), Brit. med. $\mathscr{F}, 1,472$.

35. 'Stedman's Medical Dictionary' 1958 .

36. WATTS, C. A. H., and WATTS, B. M. (1952), 'Psychiatry in General Practice.' London: Churchill.

37. WOLF, S., and WOLFF, H. G. (1947), 'Human Gastric Function, and edition. 'London: Oxford University Press.

38. WOLFF, H. G. (1952), 'Stress and Disease.' Springfield: Thomas.

\section{No time for reading?}

The face of modern medicine is constantly changing as new concepts, new methods, new developments of every kind, are reported from the clinical and research centres of the world.

To keep abreast with the tide of progress you need time-time to read and to read widely-time that can ill be spared ...

\section{ABSTRACTS OF WORLD MEDICINE saves you time . . .}

Every month its pages contain concise, informative, readable abstracts of the best of the original pafers published throughout the world, selected for you from over I,500 journals.

\section{ABSTRACTS OF WORLD MEDICINE saves YOUR time ...}

Subscriptions may be sent to, or a specimen copy obtained from Publishing Manager, B.M.A. House, Tavistock Square, London, W.C.I. Annual Subscription (12 issues) $£ 44$ s.

U.S.A. and Canada \$13.50. 